\title{
A 3-year follow-up of the Silent Diabetes Study
}

\author{
Oliver Schnell • Rolf Doerr • Volker Lodwig • \\ Joerg Weissmann • Tobias Lohmann
}

Received: 10 July 2014 / Accepted: 29 August 2014 / Published online: 17 September 2014

(C) Springer-Verlag Berlin Heidelberg 2014

Keywords Coronary artery disease $\cdot$ Diabetes $\cdot$ Mortality . Oral glucose tolerance test

$\begin{array}{ll}\text { Abbreviations } \\ \text { CAD } & \text { Coronary artery disease } \\ \text { FPG } & \text { Fasting plasma glucose } \\ \text { hs-CRP } & \text { High-sensitivity C-reactive protein } \\ \text { NT-proBNP } & \text { N-terminal pro-brain natriuretic peptide }\end{array}$

To the Editor: The Silent Diabetes Study compared the results of $\mathrm{HbA}_{1 \mathrm{c}}$ measurement with those of an OGTT in 1,015 patients without pre-diagnosed diabetes undergoing coronary angiography [1]. All patients provided written informed consent and the study was performed in accordance with the Declaration of Helsinki. Ethics approval was obtained from the local ethics committee (Saechsische Landesaerztekammer, Registration Number EK-BR-36/06-1). According to OGTT measurements, $14 \%$ were diagnosed with diabetes; but on the basis of $\mathrm{HbA}_{1 \mathrm{c}}$ measurements, only $4 \%$ were diagnosed with diabetes. In the entire group, the prevalence of newly detected impaired glucose regulation was $49 \%$. The proportion of patients with impaired glucose tolerance and diabetes increased with the extent of coronary artery disease (CAD) [1]. Post hoc

O. Schnell $(\bowtie)$

Forschergruppe Diabetes e.V. at the Helmholtz Center Munich, Ingolstaedter Landstrasse 1, 85764 Munich, Neuherberg, Germany e-mail: oliver.schnell@lrz.uni-muenchen.de

R. Doerr

Praxisklinik Herz und Gefaesse, Dresden, Germany

V. Lodwig $\cdot$ J. Weissmann

Roche Diagnostics, Mannheim, Germany

T. Lohmann

Dresden-Neustadt Hospital, Dresden, Germany pairwise comparisons showed differences in mean $2 \mathrm{~h}$ postload plasma glucose between the patients without CAD and the groups with single-, double- and triple-vessel disease (all $p<0.0001)$. Differences were also seen between the minor $\mathrm{CAD}$ group and the groups with single-, double- and triplevessel disease (all $p<0.0001$ ). $\mathrm{HbA}_{1 \mathrm{c}}$ levels, however, showed no differences among the groups with different extents of $\mathrm{CAD}$ [1].

The aim of the 3-year follow-up of the Silent Diabetes Study was to analyse the mortality and to retrospectively identify baseline risk factors for mortality. The follow-up analysis was performed in $886(87.3 \%)$ of the 1,015 patients. No information was obtained from 129 patients (12.7\%). At follow-up, 825 (93.1\%) patients had survived and 61 patients $(6.9 \%)$ had died. Table 1 compares baseline variables in survivors and non-survivors at the 3-year follow-up.

At follow-up, 25 (5.5\%) of 426 patients, who had been defined as normoglycaemic by OGTT at baseline, had died. Among 434 patients with impaired glycaemic control (impaired fasting glucose, impaired glucose tolerance, diabetes) at baseline, $36(8.3 \%)$ had died.

Baseline $\mathrm{HbA}_{1 \mathrm{c}}$, fasting plasma glucose levels (FPG) and $2 \mathrm{~h}$ post-load plasma glucose levels ( $2 \mathrm{~h}$ OGTT) were not significantly different between survivors and non-survivors: $\left(\mathrm{HbA}_{1 \mathrm{c}}: 5.6 \%\right.$ vs $5.7 \%$ [ $\left.37.7 \mathrm{vs} 38.8 \mathrm{mmol} / \mathrm{mol}\right], p=0.853$; FPG: 4.4 vs $4.3 \mathrm{mmol} / 1, p=0.639 ; 2$ h OGTT: 8.0 vs $8.6 \mathrm{mmol} / \mathrm{l}, p=0.068$ ). Baseline differences between survivors and non-survivors, however, were seen between the $2 \mathrm{~h}$ OGTT and FPG levels ( $\Delta 2 \mathrm{~h}$ OGTT-FPG).

Those who died presented with a higher baseline mean $\Delta 2 \mathrm{~h}$ OGTT-FPG compared with that of the survivors (4.26 vs $3.54 \mathrm{mmol} / 1, p=0.034$ ). A relationship between the extent of CAD and the mean $\Delta 2 \mathrm{~h}$ OGTT-FPG was also present at baseline: no CAD $(2.30 \mathrm{mmol} / \mathrm{l}, 2.28 \mathrm{SD}, 2.00$ median); beginning CAD (2.71 mmol/1, 2.49 SD, 2.00 median); single-vessel disease (3.68 mmol/l, $2.67 \mathrm{SD}, 3.00$ 
Table 1 Comparison of data in survivors and deceased patients

\begin{tabular}{|c|c|c|c|}
\hline Variable & Survivors, $n=825$ & Non-survivors, $n=61$ & $p$ value \\
\hline Age (years) & $72.7 \pm 8.63(73.7)$ & $77.7 \pm 9.14(78.8)$ & $<0.0001$ \\
\hline $\begin{array}{l}\text { Male } \\
\text { Female }\end{array}$ & $\begin{array}{l}563(68.2 \%) \\
262(31.8 \%)\end{array}$ & $\begin{array}{l}44(72.1 \%) \\
17(27.9 \%)\end{array}$ & 0.571 \\
\hline BMI $\left(\mathrm{kg} / \mathrm{m}^{2}\right)$ & $27.5 \pm 3.72(27.0)$ & $27.3 \pm 4.7(26.8)$ & 0.41 \\
\hline Systolic BP (mmHg) & $141 \pm 17.5(140)$ & $139 \pm 18.9(140)$ & 0.472 \\
\hline Diastolic BP (mmHg) & $78 \pm 9.1(80)$ & $78 \pm 8.6(80)$ & 0.716 \\
\hline BG, fasting (mmol/l) & $4.4 \pm 0.8(4.0)$ & $4.3 \pm 0.7(4.0)$ & 0.639 \\
\hline BG, 2 h OGTT $(\mathrm{mmol} / \mathrm{l})$ & $8.0 \pm 2.9(8.0)$ & $8.6 \pm 2.9(8.0)$ & 0.068 \\
\hline$\Delta 2 \mathrm{~h}$ OGTT-FPG $(\mathrm{mmol} / \mathrm{l})$ & $3.54 \pm 2.63(3.00)$ & $4.26 \pm 2.65(4.00)$ & 0.034 \\
\hline $\begin{array}{l}\mathrm{HbA}_{1 \mathrm{c}}(\%) \\
\mathrm{HbA}_{1 \mathrm{c}}(\mathrm{mmol} / \mathrm{mol})^{\mathrm{a}}\end{array}$ & $\begin{array}{l}5.6 \pm 0.6(6.0) \\
37.7(42.1)\end{array}$ & $\begin{array}{l}5.7 \pm 0.5(6.0) \\
38.8(42.1)\end{array}$ & 0.853 \\
\hline Haemoglobin (mmol/l) & $8.9 \pm 0.8(8.9)$ & $8.6 \pm 1.1(8.7)$ & 0.062 \\
\hline Leucocytes $\left(\times 10^{9} / 1\right)$ & $6.9 \pm 1.76(7.0)$ & $7.4 \pm 2.3(7.0)$ & 0.044 \\
\hline Thrombocytes $\left(\times 10^{9} / 1\right)$ & $229 \pm 63(226)$ & $227 \pm 76.6(217)$ & 0.635 \\
\hline Creatinine $(\mu \mathrm{mol} / \mathrm{l})$ & $89.9 \pm 36.0(87.0)$ & $105.5 \pm 68.8(93.0)$ & 0.078 \\
\hline Estimated GFR (ml/min) & $76.0 \pm 18.3(75.0)$ & $72.0 \pm 25.9(71.0)$ & 0.168 \\
\hline hs-CRP (nmol/l) & $47.60 \pm 80.0(21.0)$ & $116.2 \pm 270.54(36.2)$ & 0.006 \\
\hline NT-proBNP (pg/ml) & $447 \pm 618(211)$ & $1214 \pm 1060(874)$ & $<0.0001$ \\
\hline \multicolumn{4}{|l|}{ CAD } \\
\hline $\begin{array}{l}\text { No CAD } \\
\text { Minor CAD }\end{array}$ & $\begin{array}{l}53(6.4 \%) \\
145(17.6 \%)\end{array}$ & $\begin{array}{l}0(0 \%) \\
7(11.5 \%)\end{array}$ & 0.45 \\
\hline Single-vessel disease & $184(22.3 \%)$ & $11(18.0 \%)$ & \\
\hline Double-vessel disease & $183(22.2 \%)$ & $20(32.8 \%)$ & \\
\hline Triple-vessel disease & $259(31.4 \%)$ & $23(32.7 \%)$ & \\
\hline \multicolumn{4}{|l|}{ Glycaemic status } \\
\hline Normoglycaemia & $426(51.7 \%)$ & $25(41.0 \%)$ & 0.113 \\
\hline Impaired fasting glucose & $8(1.0 \%)$ & $1(1.6 \%)$ & 0.476 \\
\hline Impaired glucose tolerance & $274(33.3 \%)$ & $23(37.7 \%)$ & 0.485 \\
\hline Diabetes & $116(14.1 \%)$ & $12(19.7 \%)$ & 0.256 \\
\hline
\end{tabular}

Data are presented as mean $\pm \mathrm{SD}$ (median) or $n(\%)$ unless otherwise indicated

${ }^{\text {a }}$ Data are presented as mean (median)

BG, blood glucose

median); double-vessel disease (3.86 mmol/1, 2.62 SD, 4.00 median) and triple-vessel disease ( $4.17 \mathrm{mmol} / 1,2.53 \mathrm{SD}, 4.00$ median). Post hoc pairwise comparisons of baseline $\Delta 2 \mathrm{~h}$ OGTT-FPG showed significant differences between the no CAD group and the groups with single-, double- and triplevessel disease (all $p<0.0001$ ). Significant differences were also seen between the minor CAD group and the groups with single-, double- and triple-vessel disease (all $p<0.0001$ ), and between single- and triple-vessel disease groups $(p=0.025)$. No significant differences were observed between the no CAD and minor CAD groups $(p=0.286)$, between the single- and double-disease groups $(p=0.497)$ and between the double- and triple-disease groups $(p=0.142)$.

Differences in mortality were seen between the patients without $\mathrm{CAD}$ and those in the groups with different extents of CAD at baseline $(p=0.045)$. Among the deceased patients,
$11.5 \%$ had been diagnosed with minor CAD at baseline, $18.0 \%$ with single-vessel, $32.8 \%$ with double-vessel and $32.7 \%$ with triple-vessel disease. Among the survivors, the percentages were: $6.4 \%$ (no CAD), 17.6\% (minor CAD), $22.3 \%$ (single-vessel disease), $22.2 \%$ (double-vessel disease) and $31.4 \%$ (triple-vessel disease).

A significant relationship with mortality risk was also found for N-terminal pro-brain natriuretic peptide (NTproBNP) and high-sensitivity C-reactive protein (hs-CRP). At baseline, mean NT-proBNP was 1,214 pg/ml among the 61 deceased patients vs $447 \mathrm{pg} / \mathrm{ml}$ among the 825 survivors $(p<0.0001)$. For hs-CRP, the levels were 116.2 among deceased patients vs $47.6 \mathrm{nmol} / 1$ for the survivors $(p=0.006)$. Age, but not sex, was found to be related to mortality.

The 3-year follow-up of the Silent Diabetes Study extends the knowledge on risk factors for mortality in patients without 
pre-diagnosed diabetes undergoing coronary angiography. $\mathrm{HbA}_{1 \mathrm{c}}$ at baseline was not related to the 3 -year outcome. In addition, baseline FPG and $2 \mathrm{~h}$ post-load plasma glucose of the OGTT was not different between survivors and non-survivors. It is of interest that the difference between the $2 \mathrm{~h}$ OGTT and FPG of the OGTT at baseline was different in survivors and non-survivors. This could indicate that glycaemic variability plays a prognostic role. In line with this, an impact of glucose variability on cardiovascular outcome has been reported [2,3]. The non-significant difference in $2 \mathrm{~h}$ post-load plasma glucose ( $8.6 \mathrm{vs} 8.0 \mathrm{mmol} / \mathrm{l} ; p=0.068$ ) may also support the view.

C-reactive protein on admission has previously been found to be a strong predictor for hospital mortality in both diabetic and non-diabetic patients with an acute myocardial infarction [4]. The predictive value of NT-pro BNP for mortality is also confirmed by a recently published study in patients who underwent elective or acute coronary angiography [5].

The 3-year follow-up of the Silent Diabetes Study emphasises the impact of glucose variability as well as inflammatory and structural cardiac processes for a potential adverse outcome in patients undergoing coronary angiography.

Funding The study was sponsored by an unrestricted research grant from Roche Diagnostics GmbH, Mannheim, Germany.

Duality of interest The study was sponsored by an unrestricted research grant from Roche Diagnostics GmbH, Mannheim, Germany.
Contribution statement OS was involved in the conception and design, analysis and interpretation of data, drafting the article, revising it critically for important intellectual content and approved the final version of the paper. RD and TL carried out analysis and interpretation of the data, revised the article critically for important intellectual content and had final approval of the version to be published. VL and JW were involved in interpretation of data, revising the article critically for important intellectual content and had final approval of the version to be published. Oliver Schnell is the guarantor of this work.

\section{References}

1. Doerr R, Hoffmann U, Otter W et al (2011) Oral glucose tolerance test and $\mathrm{HbA}_{1 \mathrm{c}}$ for diagnosis of diabetes in patients undergoing coronary angiography: [corrected] the Silent Diabetes Study. Diabetologia 54:2923-2930

2. Hirakawa $Y$ et al (2014) Impact of visit-to-visit glycemic variability on the risks of macrovascular and microvascular events and all-cause mortality in type 2 diabetes: The ADVANCE Trial. Diabetes Care 37:2359-2365

3. Temelkova-Kurktschiev TS et al (2000) Postchallenge plasma glucose and glycemic spikes are more strongly associated with atherosclerosis than fasting glucose or $\mathrm{HbA}_{1 \mathrm{c}}$ level. Diabetes Care 23:1830-1834

4. Otter W, Winter M, Doering W, Standl E, Schnell O (2007) C-reactive protein in diabetic and nondiabetic patients with acute myocardial infarction. Diabetes Care 30:3080-3082

5. Ruwald MH, Goetze JP, Bech J et al (2014) NT-ProBNP independently predicts long-term mortality in patients admitted for coronary angiography. Angiology 65:31-36 